\title{
Green chemistry solutions for sol-gel micro-encapsulation of phase change materials for high-temperature thermal energy storage
}

\author{
Maria Dolores Romero-Sanchez ${ }^{1,2}$, Radu-Robert Piticescu ${ }^{2, *}$, Adrian Mihail Motoc ${ }^{2}$, Francisca Aran-Ais ${ }^{1}$, and \\ Albert Ioan Tudor ${ }^{2}$ \\ ${ }^{1}$ INESCOP, Centre for Technology and Innovation, Elda-Alicante, Spain \\ 2 National R\&D Institute for Nonferrous and Rare Metals, 102 Biruintei Blvd, Pantelimon, Ilfov, Romania
}

Received: 15 November 2017 / Accepted: 18 January 2018

\begin{abstract}
NaNO}_{3}$ has been selected as phase change material (PCM) due to its convenient melting and crystallization temperatures for thermal energy storage (TES) in solar plants or recovering of waste heat in industrial processes. However, incorporation of $\mathrm{PCMs}$ and $\mathrm{NaNO}_{3}$ in particular requires its protection (i.e. encapsulation) into containers or support materials to avoid incompatibility or chemical reaction with the media where incorporated (i.e. corrosion in metal storage tanks). As a novelty, in this study, microencapsulation of an inorganic salt has been carried out also using an inorganic compound $\left(\mathrm{SiO}_{2}\right)$ instead of the conventional polymeric shells used for organic microencapsulations and not suitable for high temperature applications (i.e. 300-500 ${ }^{\circ} \mathrm{C}$ ). Thus, $\mathrm{NaNO}_{3}$ has been microencapsulated by sol-gel technology using $\mathrm{SiO}_{2}$ as shell material. Feasibility of the microparticles synthetized has been demonstrated by different experimental techniques in terms of TES capacity and thermal stability as well as durability through thermal cycles. The effectiveness of microencapsulated $\mathrm{NaNO}_{3}$ as TES material depends on the core:shell ratio used for the synthesis and on the maximum temperature supported by $\mathrm{NaNO}_{3}$ during use.
\end{abstract}

Keywords: thermal energy storage / microencapsulation / sol-gel / inorganic salt / phase change material / $\mathrm{NaNO}_{3} /$ concentrated solar power

\section{Introduction}

Thermal energy storage (TES) using phase change materials (PCMs, for latent heat storage) is a key technology in improving efficiency of Concentrated Solar Power Plant (CSP) where solar heat can be stored for electricity production when sunlight is not available or to recover waste heat in industrial processes. However, the use of PCMs for TES is currently facing different problems, such as the lack of thermal stability of the energy storage materials, loss of effectiveness and/or serious corrosion problems when working at high temperatures (in this context, high temperature is considered when storage is performed between 120 and $600{ }^{\circ} \mathrm{C}$ ) [1-3]. Therefore, incorporation of PCMs into TES systems requires its encapsulation into containers or support materials to avoid incompatibility or reactivity problems within the media where incorporated (i.e. corrosion in metal storage tanks).

\footnotetext{
* e-mail: rpiticescu@imnr.ro
}

Macro- $(>1 \mathrm{~mm})$ and microencapsulation ( $\mu \mathrm{m}$ or $\mathrm{nm}$ particle size) procedures have been successfully developed and patented for low temperature PCMs (organic and inorganic materials), mainly using polymeric shells [4-9], which cannot be used for high temperature applications. There are also some literature and even TES pilot installations using macroencapsulated inorganic salts. Zn, $\mathrm{NaNO}_{3}, \mathrm{MgCl}_{2}$, and eutectic mixtures with melting temperatures higher than $300^{\circ} \mathrm{C}$ have been encapsulated according to US2011/0259544 [10] using Ni or carbon and stainless steel materials in the form of cylinders as containers, with $\mathrm{mm}$ to $\mathrm{cm}$ size. Patent US2012/0055661 [11] addresses to the encapsulation of molten salt nitrates in metal tubes which are sealed off for permanent containment. Recently, a procedure has been patented (US 2015/0284616) [12] for the encapsulation of molten salts such as $\mathrm{NaNO}_{3}$ or $\mathrm{KNO}_{3}$. This method is based on the coating of the PCM pellet ( $27 \mathrm{~mm}$ size) with a flexible polymer followed by metal coating by electroless and electroplating processes (Ni, $\mathrm{Cu}, \mathrm{Zn}, \mathrm{Zn}-\mathrm{Fe}$ alloys, etc.). Using electroplating method, other authors (Maruoka et al.) have obtained particles ( $3 \mathrm{~mm}$ diameter) with lead-nickel core-shell structure suitable for heat recovery of high 


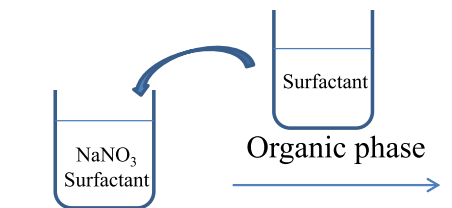

Aqueous phase

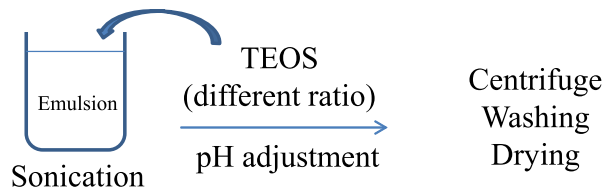

Sonication $\mathrm{pH}$ adjustment

Scheme 1. Experimental procedure for $\mathrm{NaNO}_{3}-\mathrm{SiO}_{2}$ microparticles.

temperature waste heat [13]. More simple methods can also be used for the encapsulation of metal PCMs such as indium (melting temperature $=156^{\circ} \mathrm{C}$ ) by using silica as shell by sol-gel procedure and obtaining $\mathrm{nm}$ size particles [14]. However, this method requires the melting of the metal, with increased difficultness for handling when using metals with higher melting temperature. Authors have proposed sol-gel processes using organic polymers with high melting temperature (i.e. polyimide) and organic-inorganic hybrids shells for the microencapsulation of PCMs. In this sense, stainless steel has been coated by sol-gel procedure of hybrid coatings for corrosion protection with interesting results, forming a physical barrier towards corrosion $[15,16]$. However, although interesting studies have been carried out, neither suitable solutions for microencapsulation of inorganic PCMs in the range of $300-500{ }^{\circ} \mathrm{C}$ have been successfully encountered with the requirements for TES applications nor any product can be currently found in the market.

$\mathrm{NaNO}_{3}$ has been identified in literature by several authors with thermal properties suitable for energy storage in CSP systems [17-22]. In this study, the objective is its microencapsulation using in situ synthetized $\mathrm{SiO}_{2}$ shell by sol-gel procedure as a soft chemical synthesis procedure. Influence of $\mathrm{NaNO}_{3}$ and $\mathrm{SiO}_{2}$ precursors molar ratio on the TES capacity of microencapsulated $\mathrm{NaNO}_{3}$ has been evaluated, as well as thermal stability through thermal cycles, as a method to evaluate the durability of synthetized materials and feasibility for TES [21].

\section{Experimental}

\subsection{Materials and experimental procedure}

Sodium nitrate salt $\left(\mathrm{NaNO}_{3}, 99.99 \%\right.$ purity, Merck) has been selected as PCM to be microencapsulated, due to its convenient melting temperature for TES in CSP. $\mathrm{NaNO}_{3}$ is water soluble $(2 \mathrm{~g} / 10 \mathrm{~mL})$.

Sol-gel technique has been used for the microencapsulation of $\mathrm{NaNO}_{3}$ into $\mathrm{SiO}_{2}$ shells. Tetraethylorthosilicate (TEOS, Sigma-Aldrich) has been used as $\mathrm{SiO}_{2}$ precursor.

Firstly, an aqueous phase containing hexadecyltrimethylammonium bromide (CTAB, Sigma-Aldrich) and $\mathrm{NaNO}_{3}$ is prepared. An organic phase containing cyclohexane $(\mathrm{CH}$, analysis grade, Merck) as solvent and Span 80 (Fluka) as surfactant is added drop by drop to the aqueous phase. An emulsion is obtained after vigorous stirring and sonication (2 min, 50\% intensity, Branson Digital Sonication). Subsequently, corresponding amounts of TEOS $\left(\mathrm{NaNO}_{3}: \mathrm{SiO}_{2}\right.$ molar ratio 1:0.5 and 1:0.25) are added drop by drop to the emulsion. $\mathrm{NaOH} 1 \mathrm{~N}$ was used to adjust $\mathrm{pH}$ to 11 for hydrolysis of TEOS to $\mathrm{SiO}_{2}$ in alkaline media. After $12 \mathrm{~h}$ stirring, solution is twice centrifuged and washed with $\mathrm{CH}$. Product obtained was dried in an oven at $40{ }^{\circ} \mathrm{C}$ for $24 \mathrm{~h}$ and subsequently at $150^{\circ} \mathrm{C}$ for $24 \mathrm{~h}$ (Scheme 1).

\subsection{Experimental techniques}

Different experimental techniques have been used for the thermal, chemical and morphological characterization of the materials obtained.

\subsubsection{Fourier Transform Infrared Spectroscopy (FT-IR)}

It has been used to detect the chemical groups present in the particles and compared to the chemical composition of the raw materials.

The FT-IR spectra of the samples have been obtained using a Varian 660 FT-IR spectrophotometer (Varian, Inc.) with dry $\mathrm{KBr}$ pellets prepared using a manual hydraulic press. FT-IR spectra in absorbance mode were recorded (100 scans with $4 \mathrm{~cm}^{-1}$ resolution) among the range of $600-4000 \mathrm{~cm}^{-1}$.

\subsubsection{Scanning Electron Microscopy (SEM)}

The surface morphology of the microparticles was obtained using a Phenom TM Electron Microscope system (SEM). For the SEM imaging, a drop of the corresponding microparticles dispersed in absolute ethanol was deposited on the sample holder and allowed to dry. The energy of the electron beam was $15 \mathrm{kV}$. This technique has been also used to estimate particle size. Field emission scanning electron microscopy (FESEM) has also been used for the characterization of morphology (Merlin VP Compact, Zeiss) working at higher resolution and reduced voltage $(2 \mathrm{kV})$ minimizing charging effects.

\subsubsection{Thermal Gravimetry Analysis (TGA)}

TGA (TGA/Differential scanning calorimetry (DSC) $1 \mathrm{SF}$ Star ${ }^{\text {e }}$ System, Mettler Toledo) has been used to evaluate thermal stability of the microparticles. Samples have been heated till $400^{\circ} \mathrm{C}$ at $10^{\circ} \mathrm{C} / \mathrm{min}$ under $\mathrm{N}_{2}$ atmosphere. 


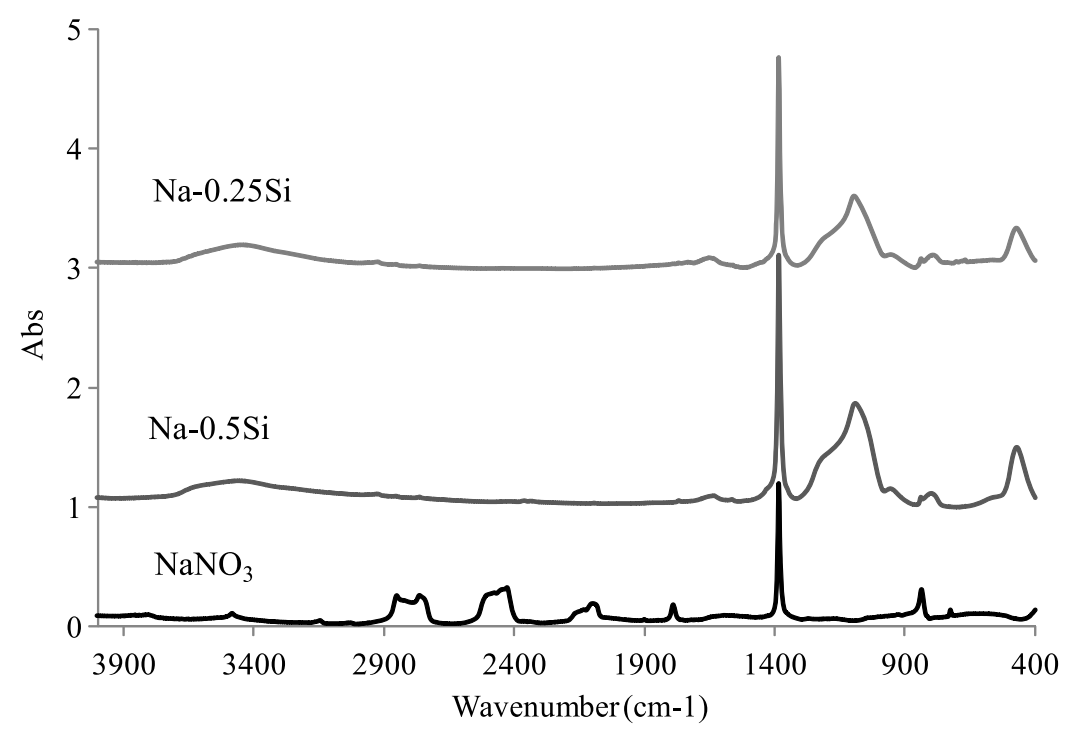

Fig. 1. FTIR spectra of $\mathrm{NaNO}_{3}$ and synthetized $\mathrm{Na}-0.5 \mathrm{Si}$ and $\mathrm{Na}-0.25 \mathrm{Si}$ microparticles.

\subsubsection{Differential Scanning Calorimetry (DSC)}

Thermal properties of the microparticles obtained with the inorganic shell have been measured by using DSC. A DSC1/700 Star ${ }^{\mathrm{e}}$ system, Mettler Toledo) Differential Scanning Calorimeter has been used at a heating rate of $10^{\circ} \mathrm{C} / \mathrm{min}$ among the range of $50-400^{\circ} \mathrm{C}$, with a sample weight of about $15 \mathrm{mg}$ and under $\mathrm{N}_{2}$ atmosphere.

Thermal analysis of the particles has been carried out during heating and cooling processes. Melting and crystallization temperatures and enthalpies have been calculated. Moreover, to evaluate thermal stability and durability of the microparticles, several thermal cycles have been carried out and melting and crystallization enthalpies have been calculated for comparison.

\section{Results and discussion}

$\mathrm{NaNO}_{3}-\mathrm{SiO}_{2}$ microparticles have been synthetized by solgel procedure using 1:0.5 and 1:0.25 molar ratios for $\mathrm{NaNO}_{3}$ :TEOS (as $\mathrm{SiO}_{2}$ precursor), with the corresponding nomenclature $\mathrm{Na}-0.5 \mathrm{Si}$ and $\mathrm{Na}-0.25 \mathrm{Si}$, respectively. The objective is to optimize this ratio to avoid the leakage of $\mathrm{NaNO}_{3}$ when melted or the shielding of $\mathrm{NaNO}_{3}$ by the $\mathrm{SiO}_{2}$ shell losing heat storage capacity.

The analysis of the chemical composition of the synthetized $\mathrm{Na}-0.5 \mathrm{Si}$ and $\mathrm{Na}-0.25 \mathrm{Si}$ is shown in the IR spectra in Figure 1.

IR spectrum of $\mathrm{NaNO}_{3}$ (Fig. 1) shows main peaks at $1385 \mathrm{~cm}^{-1}$ and $838 \mathrm{~cm}^{-1}$ due to N-O stretching vibration in $\mathrm{NO}_{3}{ }^{-}$and $2400-2500 \mathrm{~cm}^{-1}$ due to $\mathrm{N}=\mathrm{O}$ stretching vibration.

IR spectra of samples Na-0.5Si and $\mathrm{Na}-0.25 \mathrm{Si}$ are very similar and show the characteristic bands of $\mathrm{NaNO}_{3}$ at 1385 and $838 \mathrm{~cm}^{-1}$ (confirming the presence of nitrate) and the band at $1090 \mathrm{~cm}^{-1}$ ascribed to the $\mathrm{Si}-\mathrm{O}$ bond in $\mathrm{SiO}_{2}$. The band at $474 \mathrm{~cm}^{-1}$ may correspond to $\mathrm{O}-\mathrm{Si}-\mathrm{O}$ bending in $\mathrm{SiO}_{2}$ and/or asymmetric and $\mathrm{Si}-\mathrm{O}-\mathrm{Si}$ bending vibrations of the $\mathrm{SiO}_{2}$.
The band at $3440 \mathrm{~cm}^{-1}$ can be ascribed to the stretching vibration of $\mathrm{O}-\mathrm{H}, \mathrm{Si}-\mathrm{OH}$ and/or N-H groups.

The presence of both compounds, $\mathrm{NaNO}_{3}$ as $\mathrm{PCM}$ and $\mathrm{SiO}_{2}$ as shell material have been identified in the FTIR spectra of the products synthetized, with different relative intensity of the typical bands for $\mathrm{NaNO}_{3}$ and $\mathrm{SiO}_{2}$ at 1385 and $1090 \mathrm{~cm}^{-1}$, being higher for the $\mathrm{Na}-0.25 \mathrm{Si}$ microparticles (relative intensity $=2.88$ ) compared to the Na-0.5Si microparticles (relative intensity $=2.37$ ), indicating the higher proportion of $\mathrm{SiO}_{2}$ in the $\mathrm{Na}-0.5 \mathrm{Si}$ sample. Moreover, this also indicates that the bonding between $\mathrm{NaNO}_{3}$ and $\mathrm{SiO}_{2}$ is a physical bonding. Other authors have previously obtained similar results when preparing mixed systems of $\mathrm{NaNO}_{3}$ and $\mathrm{Sr}\left(\mathrm{NO}_{3}\right)_{2}$ single crystals in $\mathrm{SiO}_{2}$ media [23].

The influence of the presence of $\mathrm{SiO}_{2}$ on the thermal properties of $\mathrm{NaNO}_{3}$ has been evaluated by DSC. Thermal properties of the samples synthetized have been analyzed during heating and cooling processes from 25 to $400^{\circ} \mathrm{C}$ and 400 to $25^{\circ} \mathrm{C}$ at $10^{\circ} \mathrm{C} / \mathrm{min}$ under $\mathrm{N}_{2}$ atmosphere. Figure 2 includes the DSC thermogram for raw $\mathrm{NaNO}_{3}$ used as PCM for microencapsulation. Melting and crystallization temperatures as well as the enthalpy of the respective processes (calculated by peak integration) have been included in Table 1. Values obtained for $\mathrm{NaNO}_{3}$ agree with those obtained in literature $[24,25]$ with some slight differences due to the different conditions used for the experiments (gas for atmosphere, heating and cooling speed rate, etc). Figure 2 shows two endothermic peaks for $\mathrm{NaNO}_{3}$ during the heating process, at $278^{\circ} \mathrm{C}$ due to a solid-solid phase transition and at $306.8^{\circ} \mathrm{C}$ ascribed to the melting of $\mathrm{NaNO}_{3}$ (melting enthalpy $=158.1 \mathrm{~J} / \mathrm{g}$ ). During the cooling process, an exothermic peak releasing the energy previously stored is observed at $304^{\circ} \mathrm{C}$ and a solid phase transition at $270{ }^{\circ} \mathrm{C}$. These values of thermal properties for $\mathrm{NaNO}_{3}$ indicate the feasibility to be used as TES material. Figure 3 and Table 1 include the DSC thermograms and the quantified melting and crystallization temperatures $\left(T_{m}, T_{c}\right)$ and enthalpies $\left(\Delta H_{m}, \Delta H_{c}\right)$, respectively, for the samples $\mathrm{Na}-0.5 \mathrm{Si}$ and $\mathrm{Na}-$ $0.25 \mathrm{Si}$. 


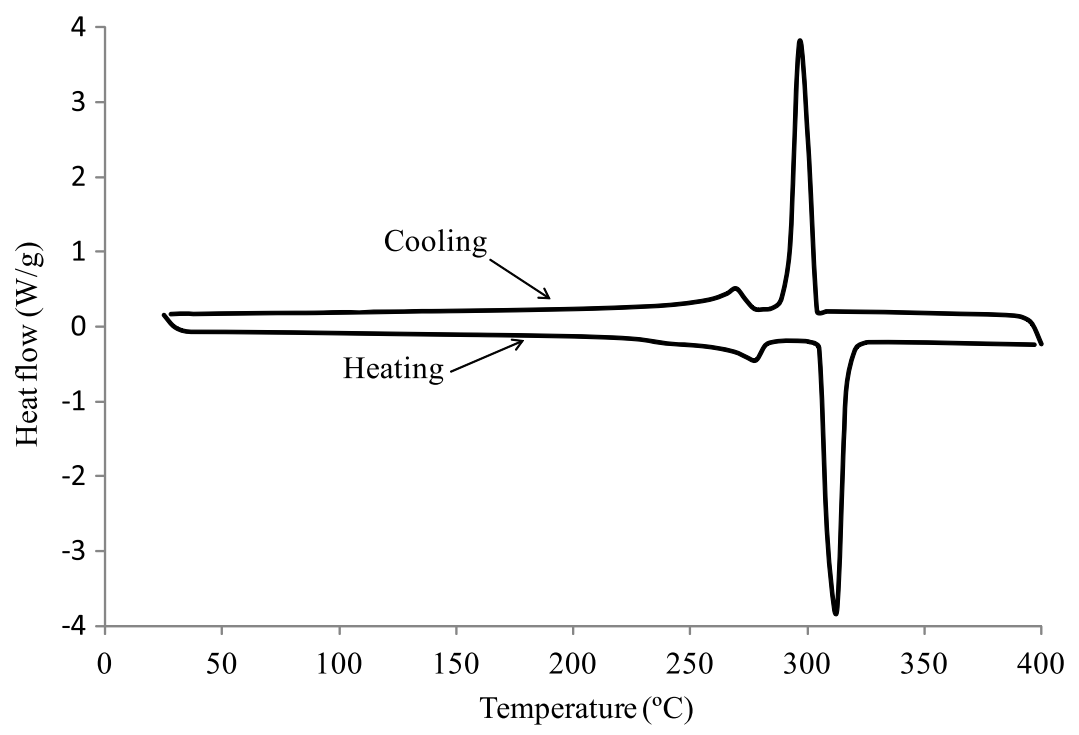

Fig. 2. DSC thermogram for $\mathrm{NaNO}_{3}$.

a)

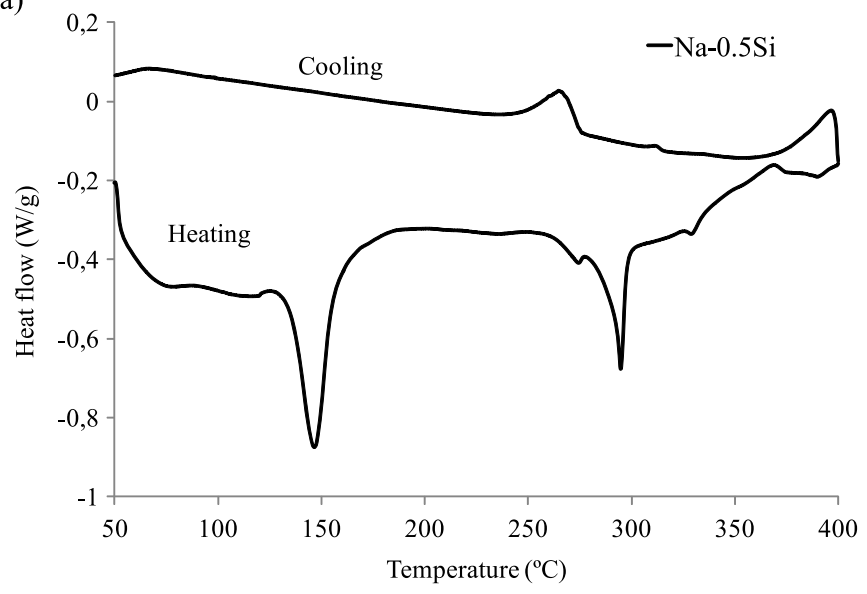

b)

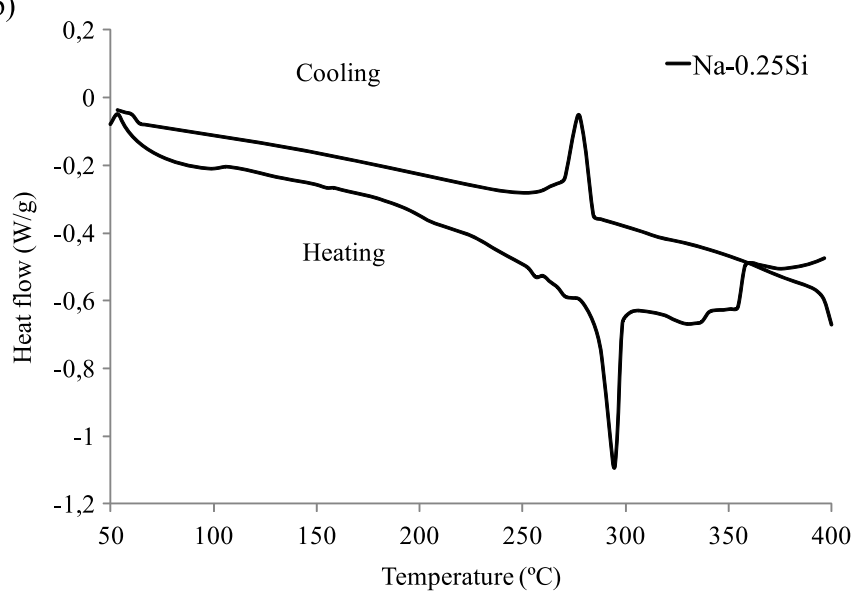

Fig. 3. DSC thermograms for (a) Na-0.5Si and (b) Na-0.25Si.

Table 1. Melting and cooling temperatures $\left(T_{m}, T_{c}\right)$ and enthalpies $\left(\Delta H_{m}, \Delta H_{c}\right)$ for raw $\mathrm{NaNO}_{3}$ and $\mathrm{Na}-0.5 \mathrm{Si}$ and Na-0.25Si microparticles. Data obtained from DSC thermograms for heating and cooling processes.

\begin{tabular}{llllll}
\hline Sample & \multicolumn{2}{c}{ Heating } & & \multicolumn{2}{c}{ Cooling } \\
\cline { 2 - 3 } \cline { 5 - 6 } & $T_{m}\left({ }^{\circ} \mathrm{C}\right)$ & $\Delta H_{m}(\mathrm{~J} / \mathrm{g})$ & & $T_{c}\left({ }^{\circ} \mathrm{C}\right)$ & $\Delta H_{c}(\mathrm{~J} / \mathrm{g})$ \\
\hline $\mathrm{NaNO}_{3}$ & 306.8 & 158.1 & & 304.0 & 159.4 \\
$\mathrm{Na}-0.5 \mathrm{Si}$ & 294.2 & 25.1 & & 264.7 & 11.2 \\
$\mathrm{Na}-0.25 \mathrm{Si}$ & 293.4 & 29.0 & & 277.5 & 21.0 \\
\hline
\end{tabular}

As observed in Figure 3, the presence of $\mathrm{SiO}_{2}$ produces some differences in the thermal behavior of synthetized $\mathrm{Na}$ $0.5 \mathrm{Si}$ and $\mathrm{Na}-0.25 \mathrm{Si}$ microparticles. In both cases, the melting temperature of $\mathrm{NaNO}_{3}$ has decreased respect to the melting temperature in the raw $\mathrm{NaNO}_{3}$. This could be explained because of the smaller particle size of the composites compared to the raw $\mathrm{NaNO}_{3}$ and the fact that $\Delta H_{m}$ and $\Delta H_{c}(\mathrm{~J} / \mathrm{g})$ for the composites have been calculated including the $\mathrm{SiO}_{2}$ weight [26-28].

$\mathrm{Na}-0.5 \mathrm{Si}$ microparticles show an endothermic peak at $146.0^{\circ} \mathrm{C}$, which may be due to impurities, as this peak does not appear when carrying out thermal cycles to Na-0.5Si microparticles and explained below.

On the other hand, the melting and cooling enthalpies of $\mathrm{Na}-0.5 \mathrm{Si}$ and $\mathrm{Na}-0.25 \mathrm{Si}$ microparticles are also affected by the presence of $\mathrm{SiO}_{2}$, with a decrease in the crystallization temperature and enthalpy respect to the raw $\mathrm{NaNO}_{3}$ due to the presence of the $\mathrm{SiO}_{2}$ which is possible to restrict the crystallization of the $\mathrm{NaNO}_{3}$ in the microparticles.

The microparticles prepared with the lower $\mathrm{SiO}_{2}$ proportion (Na-0.25Si) show the highest melting and crystallization enthalpy values. The higher the enthalpy of this peak, the higher amount of energy stored. 


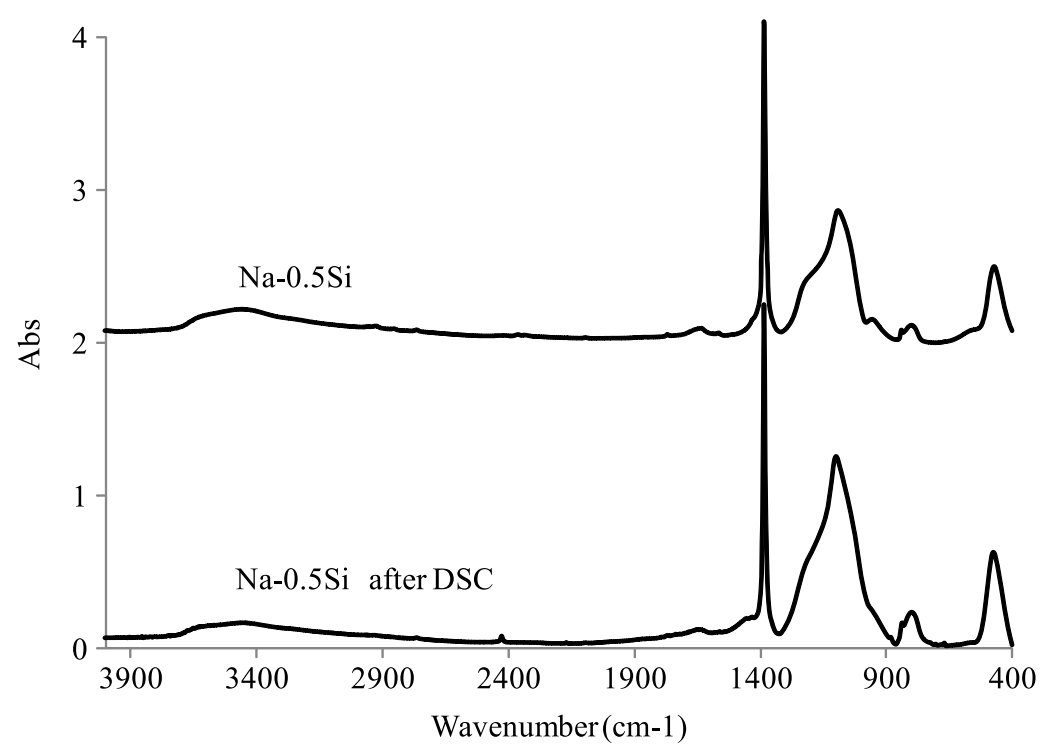

Fig. 4. FT-IR spectra of Na-0.5Si before and after DSC experiment.

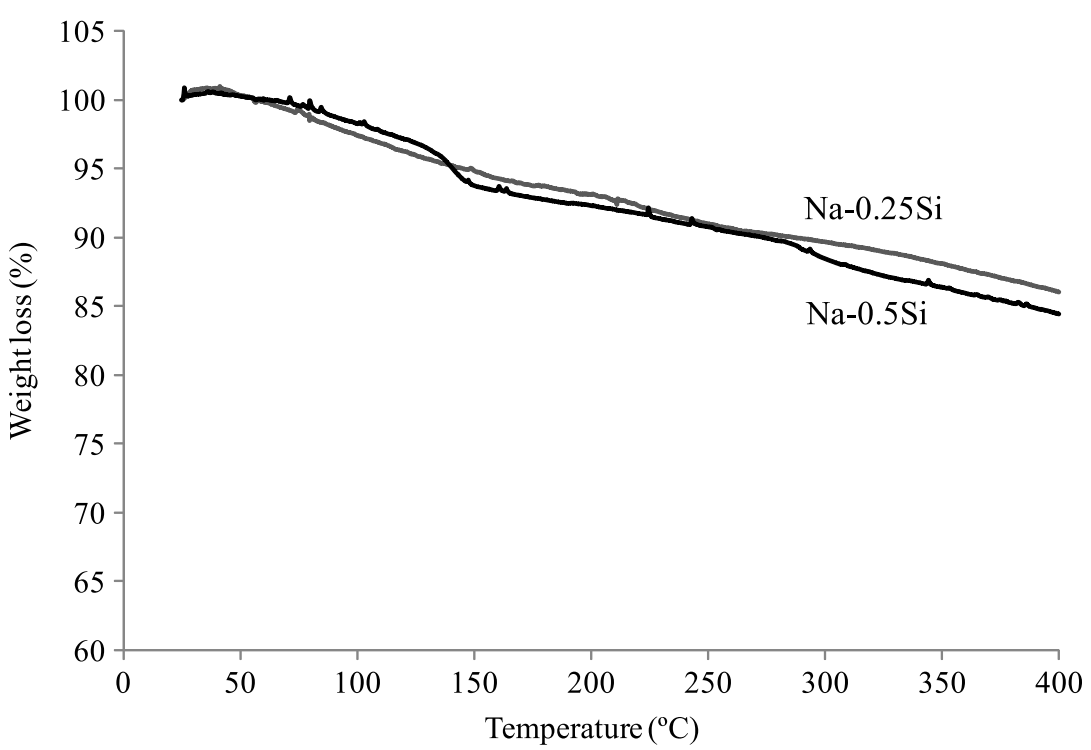

Fig. 5. TGA thermograms for raw $\mathrm{NaNO}_{3}$ and $\mathrm{Na}-0.5 \mathrm{Si}$ and $\mathrm{Na}-0.25 \mathrm{Si}$ microparticles.

The effect of the heating and cooling process on the chemical composition of the microparticles has been evaluated by FTIR spectroscopy. Figure 4 includes the FTIR spectra of $\mathrm{Na}-0.5 \mathrm{Si}$ microparticles before and after DSC experiment.

$\mathrm{Na}-0.5 \mathrm{Si}$ microparticles after DSC experiment show similar bands in the FTIR spectrum as same microparticles before DSC. The typical band for the $\mathrm{NaNO}_{3}$ appears at $1385 \mathrm{~cm}^{-1}$ and the Si-O band at $1090 \mathrm{~cm}^{-1}$. However, the relative intensity of these bands changes after the heating and cooling process in the DSC experiment. Relative intensity values of 2.33 and 1.77 (relative intensity of the bands at 1385 and $1090 \mathrm{~cm}^{-1}$ ) have been obtained for the microparticles of $\mathrm{Na}-0.5 \mathrm{Si}$ and $\mathrm{Na}-0.5 \mathrm{Si}$ after DSC, respectively, indicating a reduction of the $\mathrm{NaNO}_{3}$ proportion respect to the $\mathrm{SiO}_{2}$ in the $\mathrm{Na}-0.5 \mathrm{Si}$ microparticles after
DSC experiment. This result is in agreement with the TGA analysis carried out to the microparticles, as observed in Figure 5, for thermal stability evaluation.

Figure 5 includes the TGA thermograms for $\mathrm{Na}-0.5 \mathrm{Si}$ and $\mathrm{Na}-0.25 \mathrm{Si}$ microparticles. The Na-0.5Si microparticles suffer a first weight loss at $135^{\circ} \mathrm{C}(2.62$ wt.\%), which agrees with the endothermic peak observed in the DSC thermogram in Figure 3a and explained due to the presence of impurities of the synthesis of $\mathrm{NaNO}_{3}$ microparticles. Additionally, a slight weight reduction is also produced at $295{ }^{\circ} \mathrm{C}(1.40 \mathrm{wt} . \%)$, which corresponds to the melting temperature of $\mathrm{NaNO}_{3}$ in the microparticles determined by DSC (Tab. 1). Therefore, a decrease in the amount of $\mathrm{NaNO}_{3}$ in Na-0.5Si microparticles is produced during melting, which may be due to the transformation into other compounds such as $\mathrm{NaNO}_{2}$. Moreover, results obtained by 
a)

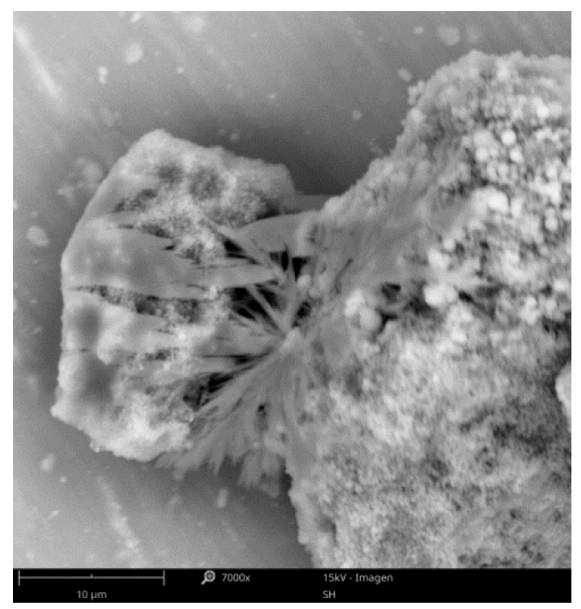

b)

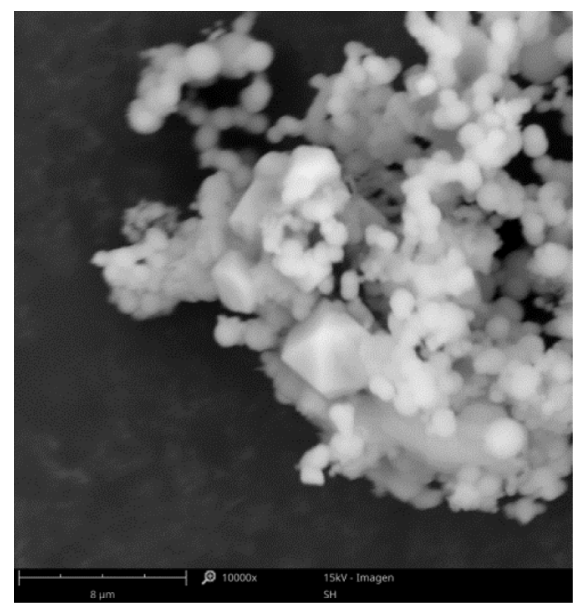

Fig. 6. SEM micrographs of (a) Na-0.5Si and (b) Na-0.25Si microparticles.

a)

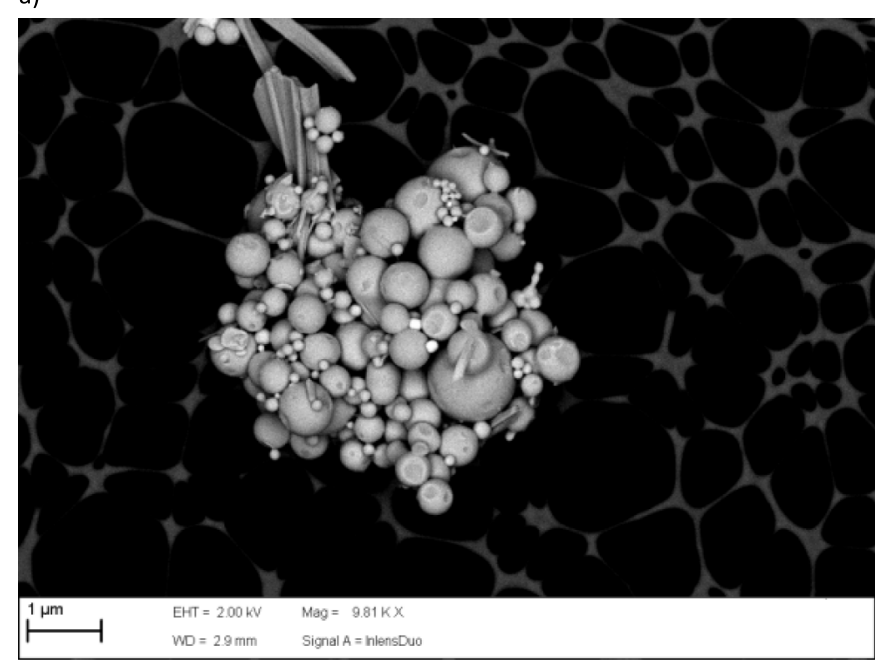

b)

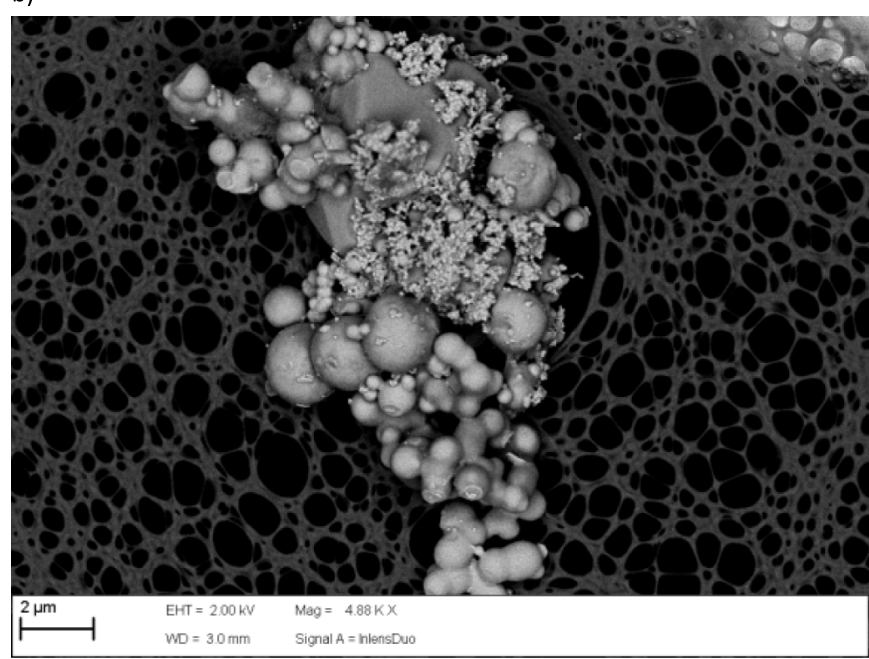

Fig. 7. FESEM micrographs of (a) Na-0.5Si and (b) Na-0.25Si microparticles.

DSC (Tab. 1) also show that the melting temperature of $\mathrm{NaNO}_{3}$ in the Na-0.5Si microparticles has decreased respect to the raw $\mathrm{NaNO}_{3}$. It is important to notice that the $\mathrm{NaNO}_{3}$ weight loss has been produced in spite of the higher proportion of $\mathrm{SiO}_{2}$ as shell material, compared to $\mathrm{Na}-0.25 \mathrm{Si}$ microparticles, which do not show any appreciable weight loss in the temperature range analyzed.

Figure 6 shows the morphology of the $\mathrm{Na}-0.5 \mathrm{Si}$ and $\mathrm{Na}-$ 0.25Si microparticles obtained by SEM. As observed in Figure 6 a for $\mathrm{Na}-0.5 \mathrm{Si}, \mathrm{NaNO}_{3}$ has crystallized as bundles coated with $\mathrm{SiO}_{2}$ microparticles (wide particle size distribution: $0.2-0.5 \mu \mathrm{m}$ ), leading to $\mathrm{NaNO}_{3}$ and $\mathrm{SiO}_{2}$ composites. However, micrographs obtained for $\mathrm{Na}-0.25 \mathrm{Si}$ microparticles show prismatic shape $\mathrm{NaNO}_{3}$ crystals coated with $\mathrm{SiO}_{2}$ microspheres (particle size $0.5-1 \mu \mathrm{m}$ ), showing an entrapment of $\mathrm{NaNO}_{3}$ crystals in $\mathrm{SiO}_{2}$ microparticles agglomerates. Similar results have been obtained by using FESEM, as included in the micrographs in Figure 7. The different morphology of the $\mathrm{NaNO}_{3}$ crystals may be explained due to the different crystal growth in the presence of different ratio of $\mathrm{SiO}_{2}$ microparticles. Many studies in literature indicate that the crystal growth strongly depends on impurities and additives in the crystallization media or solution, affecting the composition, structure and final properties of the crystal [29]. The different morphology of the $\mathrm{NaNO}_{3}$ particles leads to a different thermal behaviour, as previously observed by DSC and TGA, with better results for the $\mathrm{Na}-0.25 \mathrm{Si}$ microparticles, with the lower $\mathrm{SiO}_{2}$ proportion.

Thermal stability of the $\mathrm{Na}-0.5 \mathrm{Si}$ and $\mathrm{Na}-0.25 \mathrm{Si}$ microparticles through thermal cycles has also been evaluated. Heating and cooling thermal cycles by DSC have been carried out from 50 to $400{ }^{\circ} \mathrm{C}$ and 400 to $50{ }^{\circ} \mathrm{C}$ at $10^{\circ} \mathrm{C} / \mathrm{min}$. Melting and crystallization temperatures and enthalpies have been analyzed and included in Figure 8a and b, respectively for Na-0.5Si and Na-0.25Si and Table 2 .

Data obtained for Na-0.5Si microparticles indicate that there is a loss of heating and cooling enthalpies with thermal cycles, i.e. 5.4 and $5.9 \mathrm{~J} / \mathrm{g}$, respectively, after 16 thermal cycles. This indicates a poor thermal stability of 
a)

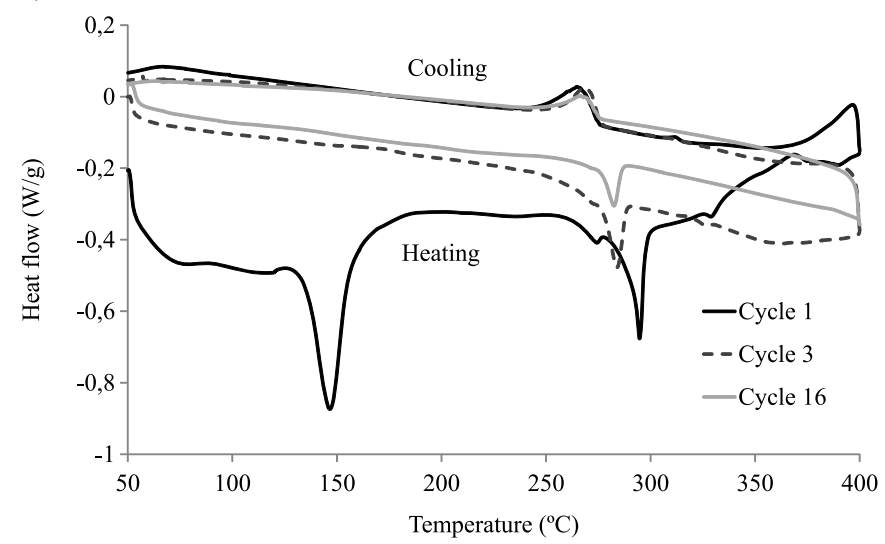

b)

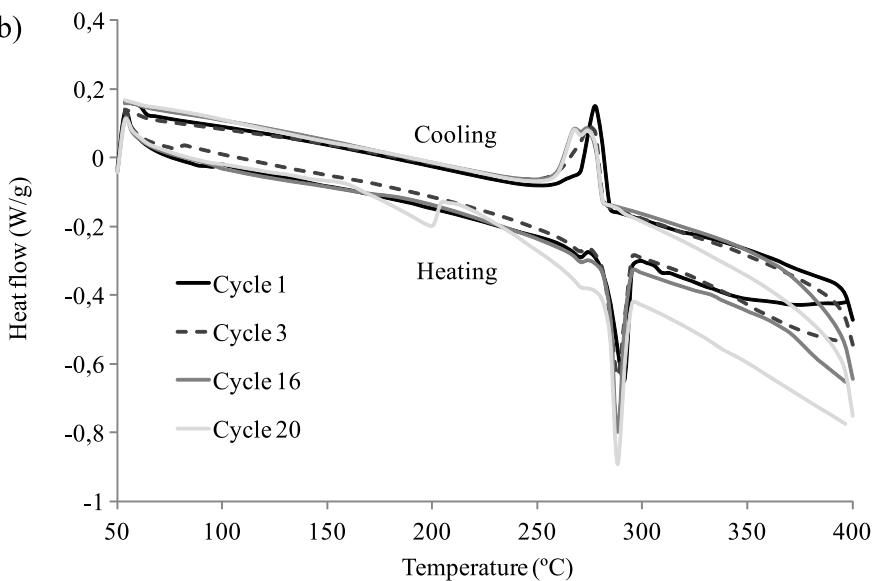

Fig. 8. DSC thermograms of thermal cycles for (a) Na-0.5Si and (b) Na-0.25Si microparticles.

Table 2. Melting and cooling temperatures $\left(T_{m}, T_{c}\right)$ and enthalpies $\left(\Delta H_{m}, \Delta H_{c}\right)$ during thermal cycles for Na-0.5Si and Na-0.25Si microparticles. Data obtained from DSC thermograms for heating and cooling processes.

\begin{tabular}{|c|c|c|c|c|}
\hline \multirow[t]{2}{*}{$\mathrm{Na}-0.5 \mathrm{Si}$} & \multicolumn{2}{|c|}{ Heating } & \multicolumn{2}{|c|}{ Cooling } \\
\hline & $T_{m}\left({ }^{\circ} \mathrm{C}\right)$ & $\Delta H_{m}(\mathrm{~J} / \mathrm{g})$ & $T_{c}\left({ }^{\circ} \mathrm{C}\right)$ & $\Delta H_{c}(\mathrm{~J} / \mathrm{g})$ \\
\hline Cycle 1 & 294.2 & 25.1 & 264.7 & 11.2 \\
\hline Cycle 2 & 283.7 & 10.9 & 268.8 & 10.7 \\
\hline Cycle 3 & 283.5 & 11.5 & 269.5 & 9.6 \\
\hline Cycle 16 & 282.3 & 5.4 & 266.3 & 5.9 \\
\hline \multirow[t]{2}{*}{$\mathrm{Na}-0.25 \mathrm{Si}$} & \multicolumn{2}{|c|}{ Heating } & \multicolumn{2}{|c|}{ Cooling } \\
\hline & $T_{m}\left({ }^{\circ} \mathrm{C}\right)$ & $\Delta H_{m}(\mathrm{~J} / \mathrm{g})$ & $T_{c}\left({ }^{\circ} \mathrm{C}\right)$ & $\Delta H_{c}(\mathrm{~J} / \mathrm{g})$ \\
\hline Cycle 1 & $270.5 ; 293.9$ & 26.2 & $281.0 ; 267.0$ & 25.7 \\
\hline Cycle 2 & $270.5 ; 290.5$ & 19.5 & $276.8 ; 267.5$ & 21.5 \\
\hline Cycle 3 & $270.5 ; 288.2$ & 20.0 & $275.1 ; 267.0$ & 22.1 \\
\hline Cycle 16 & $270.5 ; 288.1$ & 20.0 & $274.3 ; 270.5$ & 22.0 \\
\hline Cycle 20 & $270.5 ; 288.2$ & 21.9 & $274.8 ; 270.0$ & 22.7 \\
\hline
\end{tabular}

the Na-0.5Si microparticles, which agrees with the TGA results, showing a decrease in the amount of $\mathrm{NaNO}_{3}$ in the microparticles, due to the gradual transformation of $\mathrm{NaNO}_{3}-\mathrm{NaNO}_{2}$ as observed with the continuous decrease in the melting temperature when increasing the number of thermal cycles $\left(\mathrm{NaNO}_{2}\right.$ melting temperature $\left.=271^{\circ} \mathrm{C}\right)$.

On the other hand, $\mathrm{Na}-0.25 \mathrm{Si}$ microparticles prepared with a lower proportion of $\mathrm{SiO}_{2}$, show very good thermal stability even after 20 thermal cycles from 50 to $400^{\circ} \mathrm{C}$ and 400 to $50^{\circ} \mathrm{C}$, with constant melting and cooling enthalpies (values higher than 20 and $22 \mathrm{~J} / \mathrm{g}$, respectively). Main melting and crystallization temperatures are around $288^{\circ} \mathrm{C}$ and $275^{\circ} \mathrm{C}$, respectively (Tab. 2b). Moreover, it is important to notice in both the heating and cooling processes, the small peak, respectively at $270.5^{\circ} \mathrm{C}$ and $267.0^{\circ} \mathrm{C}$. These peaks may correspond to the melting and crystallization of $\mathrm{NaNO}_{2}$. The peak at $267.0^{\circ} \mathrm{C}$ increases its intensity with thermal cycles, appearing as an intense crystallization peak at $270.5^{\circ} \mathrm{C}$ in cycle 16 . This could be explained due to the decomposition of $\mathrm{NaNO}_{3}$ to $\mathrm{NaNO}_{2}$ at the DSC temperature range to $400^{\circ} \mathrm{C}$. Commonly, $\mathrm{NaNO}_{3}$ decomposition takes place at temperatures higher than $450{ }^{\circ} \mathrm{C}[30,31]$, therefore at $400^{\circ} \mathrm{C}$, a slow decomposition is produced, which gradually increases after each thermal cycle. As a difference, Na-0.5Si microparticles only show one melting and crystallization peak, which are shifted to lower melting temperatures and higher crystallization temperatures, respectively, when increasing thermal cycles. Na-0.5Si microparticles do not show the melting and crystallization peaks at 270.5 and $267.0^{\circ} \mathrm{C}$, as observed for the Na-0.25Si microparticles. Some authors have also shown the $\mathrm{NaNO}_{2}$ formation when using $\mathrm{NaNO}_{3}$ as PCM material [32]. Bauer et al. [33] have demonstrated that the presence of $\mathrm{NaNO}_{2}$ in molten $\mathrm{NaNO}_{3}$ leads to a reduction of the $\mathrm{NaNO}_{3}$ melting temperature compared to raw $\mathrm{NaNO}_{3}$. The thermal dissociation is reversible, which may explain the similar intensity of the melting peaks at $270.5^{\circ} \mathrm{C}$ when increasing thermal cycles. 


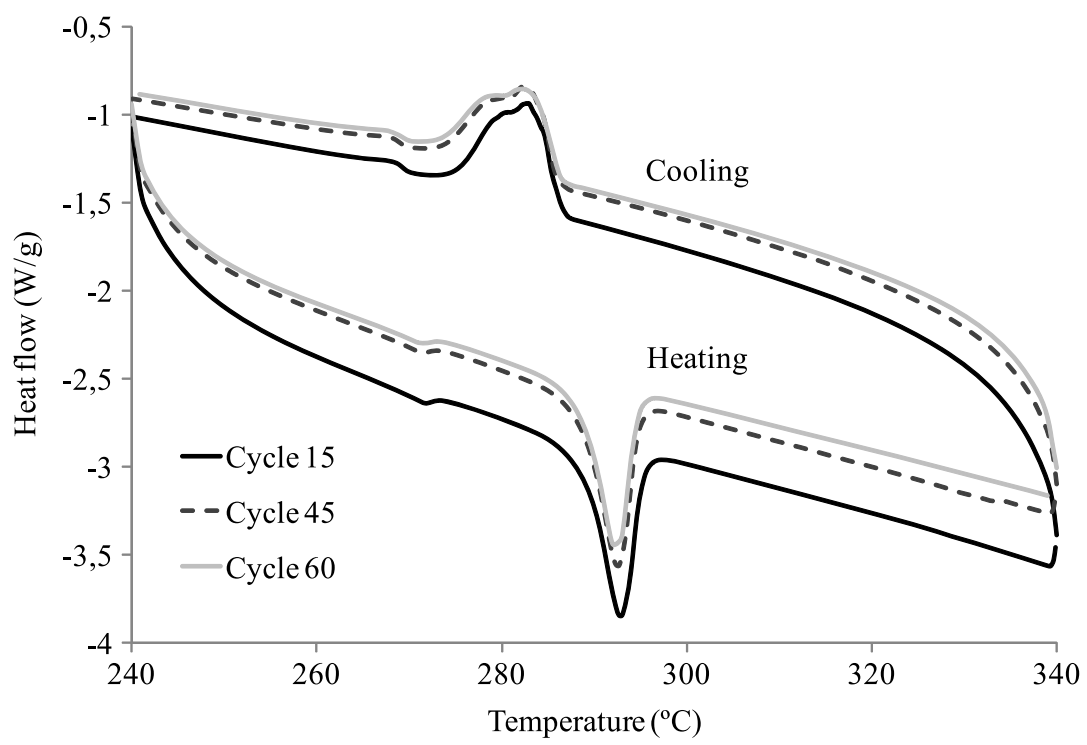

Fig. 9. DSC thermograms of thermal cycles in narrow temperature range $\left(240-340^{\circ} \mathrm{C}\right)$ for Na-0.25Si microparticles.

Table 3. Melting and cooling temperatures $\left(T_{m}, T_{c}\right)$ and enthalpies $\left(\Delta H_{m}, \Delta H_{c}\right)$ during thermal cycles in narrow temperature range $\left(240-340^{\circ} \mathrm{C}\right)$ for Na-0.25Si microparticles. Data obtained from DSC thermograms for heating and cooling processes.

\begin{tabular}{lllll}
\hline Na-0.25Si & \multicolumn{2}{c}{ Heating } & \multicolumn{2}{c}{ Cooling } \\
\cline { 2 - 4 } & $T_{m}\left({ }^{\circ} \mathrm{C}\right)$ & $\Delta H_{m}(\mathrm{~J} / \mathrm{g})$ & $T_{c}\left({ }^{\circ} \mathrm{C}\right)$ & $\Delta H_{c}(\mathrm{~J} / \mathrm{g})$ \\
\hline Cycle 1 & 294.0 & 28.3 & 283.6 & 20.3 \\
Cycle 15 & 292.0 & 26.8 & 282.8 & 26.3 \\
Cycle 30 & 291.8 & 26.2 & 283.1 & 25.7 \\
Cycle 45 & 291.7 & 26.3 & 282.2 & 25.3 \\
Cycle 60 & 291.6 & 26.2 & 283.0 & 25.3 \\
\hline
\end{tabular}

As also observed by these authors, the presence of $\mathrm{NO}_{2}{ }^{-}$ in the $\mathrm{NaNO}_{3}$ solution may lead to the changes in the $\mathrm{NaNO}_{3}$ behaviour during melting and cristallyzation processes.

As previously observed in Figure 3 and Table 1, Na$0.25 \mathrm{Si}$ microparticles show higher TES capacity (higher melting and crystallization enthalpies) than the microparticles with the higher $\mathrm{SiO}_{2}$ proportion $(\mathrm{Na}-0.5 \mathrm{Si})$. This could be expected due to the lower amount of $\mathrm{SiO}_{2}$ shielding the core $\mathrm{NaNO}_{3}$. Moreover, and according to the TGA (Fig. 5) and DSC thermograms (Fig. 8, Tab. 2), the thermal stability through thermal cycles of $\mathrm{Na}-0.5 \mathrm{Si}$ microparticles is reduced compared to the microparticles prepared with lower $\mathrm{SiO}_{2}$ ratio $(\mathrm{Na}-0.25 \mathrm{Si})$. This is an unexpected result because of the higher amount of $\mathrm{SiO}_{2}$ encapsulating and protecting the $\mathrm{NaNO}_{3}$ used as PCM in the Na-0.5Si microparticles.

In real CSP applications, PCMs are not allowed to heat or cool after each thermal cycle in a wide range of temperature around its melting and crystallization temperature. To evaluate the TES capacity of $\mathrm{Na}-0.25 \mathrm{Si}$ microparticles when subjected to thermal cycles in narrower temperature ranges, DSC technique has also been used. Melting and crystallization enthalpies have been determined to analyze the $\mathrm{NaNO}_{3}$ capacity to melt and crystallize in these narrow temperature ranges. Considering that the melting temperature of $\mathrm{NaNO}_{3}$ in the microparticles is around $290^{\circ} \mathrm{C}$, thermal cycles between 240 and $340^{\circ} \mathrm{C}$ have been carried out to $\mathrm{Na}-0.25 \mathrm{Si}$ microparticles (Fig. 9). Results included in Table 3 indicate the TES capacity of the encapsulated product even after 60 thermal cycles.

Results obtained with the thermal cycles in the temperature range between 240 and $340^{\circ} \mathrm{C}$ indicate the TES capacity of $\mathrm{NaNO}_{3}$ as PCM in the microparticles even after 60 thermal cycles, with constant melting and crystallization enthalpies higher than 26 and $25 \mathrm{~J} / \mathrm{g}$, respectively, as well as melting and crystallization temperatures $\left(291.7,283^{\circ} \mathrm{C}\right.$, respectively). As a difference with the thermal cycles in Figure $8\left(50-400^{\circ} \mathrm{C}\right)$, in this case, for the $240-340^{\circ} \mathrm{C}$ thermal cycles, the crystallization peak at $270^{\circ} \mathrm{C}$ only appears as a shoulder of the main crystallization peak at around $283^{\circ} \mathrm{C}$. This may be explained due to the lower maximum temperature applied, $340^{\circ} \mathrm{C}$, avoiding the transformation of $\mathrm{NaNO}_{3}-\mathrm{NaNO}_{2}$, previously observed in the thermal cycles carried out to $400{ }^{\circ} \mathrm{C}$. 
Hence, the effectiveness of $\mathrm{NaNO}_{3}$ microparticles to be used as PCMs is determined by the maximum temperature during use. Temperatures higher than $400{ }^{\circ} \mathrm{C}$ slightly lead to the formation of $\mathrm{NaNO}_{2}$ and therefore, modifications on the melting and crystallization temperatures and enthalpies respect to the raw $\mathrm{NaNO}_{3}$.

\section{Conclusions}

Sol-gel has been demonstrated as a feasible technology for the microencapsulation of $\mathrm{NaNO}_{3}$ using $\mathrm{SiO}_{2}$ as shell material.

Effectiveness of microencapsulated $\mathrm{NaNO}_{3}$ as TES material greatly depends on the morphology of microparticles and therefore, on the $\mathrm{NaNO}_{3}: \mathrm{SiO}_{2}$ ratio. Results have shown that $\mathrm{Na}-0.25 \mathrm{Si}$ microparticles have higher energy storage capacity even with a lower proportion of $\mathrm{SiO}_{2}$ respect to the $\mathrm{NaNO}_{3}$ core material compared with the higher ratio in $\mathrm{Na}-0.5 \mathrm{Si}$ microparticles. The $\mathrm{SiO}_{2}$ shell may affect the $\mathrm{NaNO}_{3}$ crystal growth. This indicates the great influence of experimental parameters on the effectiveness of microencapsulated materials. In this sense, deeper work is being done by the authors to analyze the influence of the $\mathrm{NaNO}_{3}$ crystal phase on its energy storage capacity when microencapsulated within $\mathrm{SiO}_{2}$ shells.

TES stability of microencapsulated $\mathrm{NaNO}_{3}$ with $\mathrm{SiO}_{2}$ depends among other factors on the maximum temperature during use. Temperatures higher than $400{ }^{\circ} \mathrm{C}$ lead to the dissociation of $\mathrm{NO}_{3}{ }^{-}$to $\mathrm{NO}_{2}^{-}$and therefore to a modification of the TES properties of $\mathrm{NaNO}_{3}$.

The authors gratefully acknowledge the financial support received from European Commission and Romanian Government-Management Authority from Ministry of Research and Innovation, in the frame of Competiveness Operational Programme, Action A1.1.4-E-2015, project ID P_37_776, SMIS code 104730, Acronym ENERHIGH.

Albert Ioan Tudor also gratefully acknowledges the financial support received from Romanian Ministry of Research and Innovation in the frame of the project PN 16200302.

\section{References}

1. A. Gil, M. Medrano, I. Martorell, A. Lázaro, P. Dolado, B. Zalba, L.F. Cabeza, State of the art on high temperature thermal energy storage for power generation. Part 1concepts, materials and modellization, Renew. Sustain. Energy Rev. 14 (2010) 31-55

2. M. Medrano, A. Gil, I. Martorell, X. Potau, L.F. Cabeza, State of the art on high-temperature thermal energy storage for power generation. Part 2-case studies, Renew. Sustain. Energy Rev. 14 (2010) 56-72

3. S. Bellan, A. Cordiviola, S. Barberis, A. Traverso, J. GonzálezAguilar, M. Romero, Numerical analysis of latent heat storage system with encapsulated phase change material in spherical capsules, Renew. Energy Environ. Sustain. 2 (2017) 3

4. M. Graham, E. Shchukina, P. Felix De Castro, D. Shchukin, Nanocapsules containing salt hydrate phase change materials for thermal energy storage, J. Mater. Chem. A 4 (2016) 16906-16912
5. D. Platte, U. Helbig, R. Houbertz, G. Sextl, Microencapsulation of salt hydrate melts for phase change applications by surface thiol-michael addition polymerization, Macromol. Mater. Eng. 298 (2013) 67-77

6. F. Salaun, E. Devaux, S. Bourbigot, P. Rumeau, Influence of the solvent on the microencapsulation of a hydrated salt, Carbohydr. Polym. 79 (2010) 964-974

7. EP 20152119498 A1, Procedure for microencapsulation of phase change materials by spray-drying

8. S. Ushak, M.J. Cruz, L.F. Cabeza, M. Grágeda, Preparation and characterization of inorganic PCM microcapsules by fluidized bed method, Materials 9 (2016) 24

9. W. Su, J. Darkwa, G. Kokogiannakis, Development of microencapsulated phase change material for solar thermal energy storage, Appl. Therm. Eng. 112 (2017) 1205-1212

10. US 2011/0259544, Encapsulated phase change apparatus for thermal energy storage

11. US 2012/0055661, High temperature thermal energy storage system

12. US 2015/0284616, Encapsulation of thermal energy storage media

13. N. Maruoka, T. Akiyama, Thermal stress analysis of PCM encapsulation for heat recovery of high temperature waste heat. J. Chem. Eng. Jpn 36 (2003) 794-798

14. Y. Hong, S. Ding, W. Wu, J. Hu, A.A. Voevodin, L. Gschwender, Ed. Snyder, L. Chow, M. Su, Enhancing heat capacity of colloidal suspension using nanoscale encapsulated phase-change materials for heat transfer, Appl. Mater. Interfaces $\mathbf{2}$ (2010)

15. P. Chou, C. Chandrasekaran, G.Z. Cao, Sol-gel derived hybrid coatings for corrosion protection, J. Sol-Gel Sci. Technol. 26 (2003) 321-327

16. R.B. Figueira, C.J.R. Silva, E.V. Pereira, Organic-inorganic hybrid sol-gel coatings for metal corrosion protection: a review of recent progress, J. Coat. Technol. Res. 12 (2015) 1-35

17. M. Liu, W. Saman, F. Bruno, Review on storage materials and thermal performance enhancement techniques for high temperature phase change thermal storage systems, Renew. Sustain. Energy Rev. 16 (2012) 2118-2132

18. B. Zalba, J.M. Marin, L.F. Cabeza, H. Mehling, Review on thermal energy storage with phase change: materials, heat transfer analysis and applications, Appl. Therm. Eng. 23 (2003) 251-283

19. S. Kuravi, J. Trahan, D. Yogi Goswami, M.M. Rahman, E.K. Stefanakos, Review thermal energy storage technologies and systems for concentrating solar power plants, Prog. Energy Combust. Sci. 39 (2013) 285-319

20. M.M. Kenisarin, High-temperature phase change materials for thermal energy storage, Renew. Sustain. Energy Rev. 14 (2010) 955-970

21. J.C. Gomez, N. Calvet, A.K. Starace, G.C. Glatzmaier, Ca $\left(\mathrm{NO}_{3}\right)_{2}-\mathrm{NaNO}_{3}-\mathrm{KNO}_{3}$ Molten Salt Mixtures for Direct Thermal Energy Storage Systems in Parabolic Trough Plants, J. Sol. Energy Eng. 135 (2013)

22. Y. Zheng, W. Zhao, J.C. Sabol, K. Tuzla, S. Neti, A. Oztekin, J.C. Chen, Encapsulated phase change materials for energy storage - characterization by calorimetry, Sol. Energy $\mathbf{8 7}$ (2013) 117-126

23. T. Vijay Kumar, A. Sadananda Chary, A.M. Awasthi, S. Bhardwaj, S. Narender Reddy, Effect of nano $\mathrm{SiO}_{2}$ on properties of structural, thermal and ionic conductivity of 85.32 $\left[\mathrm{NaNO}_{3}\right]-14.68\left[\mathrm{Sr}\left(\mathrm{NO}_{3}\right)_{2}\right]$ mixed system, Ionics 21 (2015) 1341-1349 
24. T. Jriri, J. Rogez, C. Bergman, J.C. Mathieu, Thermodynamic study of the condensed phases of $\mathrm{NaNO}_{3}, \mathrm{KNO}_{3}$ and $\mathrm{CsNO}_{3}$ and their transitions, Thermochim. Acta, 266 (1995) 147-161

25. T. Bauer, D. Laing, R. Tamme, Characterization of sodium nitrate as phase change material, Int. J. Thermophys. 33 (2012) 91-104

26. C. Alba-Simionesco, B. Coasne, G. Dosseh, G. Dudziak, K.E. Gubbins, R. Radhakrishnan, M. Sliwinska-Bartkowiak, Effects of confinement on freezing and melting, J. Phys.: Condens. Matter. 18 (2006) 15-68

27. M. Fuensanta, U. Paiphansiri, M.D. Romero-Sánchez, C. Guillem, Á.M. López-Buendía, K. Landfester, Thermal properties of a novel nanoencapsulated phase change material for thermal energy storage, Thermochim. Acta 565 (2013) 95-101

28. Q. Guo, T. Wang, Preparation and characterization of sodium sulfate/silica composite as a shape-stabilized phase change material by sol-gel method, Chin. J. Chem. Eng. 22 (2014) 360-364
29. R. Benages Vilau, Growth, Morphology and solid state miscibility of alkali nitrates, Doctoral Thesis, University of Barcelona, 2013

30. Y. Hoshino, T. Utsunomiya, O. Abe, The thermal decomposition of sodium nitrate and the effects of several oxides on the decomposition, Bull. Chem. Soc. Jpn. 54 (1981) 1385-1391

31. P. Gimenez, S. Fereres, Effect of heating rates and composition on the thermal decomposition of nitrate based molten salts, Energy Procedia 69 (2015) 654-662

32. R.W. Bradshaw, N.P. Siegel, Molten nitrate salt development for thermal energy storage in parabolic trough solar power systems, in: Proceedings of ES2008-54174. Energy Sustainability 2008 August 10-14, Jacksonville, Florida USA, 2008

33. T. Bauer, D. Laing, U. Kröner, R. Tamme, The 11th International Conference on Thermal Energy Storage Effstock in Stockholm, Sweden, 2009

Cite this article as: Maria Dolores Romero-Sanchez, Radu-Robert Piticescu, Adrian Mihail Motoc, Francisca Aran-Ais, Albert Ioan Tudor, Green chemistry solutions for sol-gel micro-encapsulation of phase change materials for high-temperature thermal energy storage, Manufacturing Rev. 5, 8 (2018) 